\title{
FURTHER OBSERVATIONS ON THE SIGNIFICANCE OF THE BLOOD PYRUVIC ACID LEVEL IN INFANCY*
}

\author{
BY
}

\author{
E. C. ALLIBONE, M.D. \\ (From the Children's Hospital, Birmingham)
}

In a previous paper it was shown (Allibone and Finch, 1946) that toxic and infective states raised the blood pyruvic acid level in spite of what normally would have been an adequate thiamine intake. This phenomenon was particularly noticeable in infancy. Two factors had now to be considered. The first was whether the vitamin was being absorbed. Diarrhoea, which obviously would interfere with absorption, is particularly common in toxic states in infancy. In the group of infants observed above, diarrhoea, though frequent, was not an invariable manifestation and in these particular cases had not been severe. Nevertheless such a possibility needed to be excluded. The second problem was whether, under such circumstances, an increased intake might be necessary to achieve the greatest metabolic efficiency. Abbasy et al. (1937) had shown that in infective states there was an increased utilization of vitamin $\mathbf{C}$ as determined by blood levels and urinary excretion. Further support for the latter possibility was to be found in the observations that the blood pyruvic acid became elevated in association with an increase in the environmental temperature (Mills, 1943) and in thyrotoxicosis (Davis and Bauer, 1944), when a raised basal metabolic rate was probably the cause.

To investigate these possibilities it was decided to follow up infants who appeared likely to have a persistently high blood pyruvic acid, that is cases of marasmus, to give such infants a trial period on a physiological dose of thiamine and then, if the blood levels remained high, to give the vitamin parenterally. If there was still no response, the next step would be to give massive doses of thiamine either orally or parenterally.

A second type of case chosen for study as possibly having a high pyruvic acid was those infants with haemolytic anaemia. Sinclair (1939) reported that haemin destroyed thiamine. In a previous paper Allibone and Finch (1945) had found gery low urinary thiamine excretion following successive

* Part of a thesis submitted for the degree of Ph.D., University of Birmingham. doses of the vitamin in two cases with haemolytic anaemia.

With regard to the first type of case studied, it was naturally impossible to be sure that a high initial pyruvic acid level would remain elevated long enough to enable the experiment to be concluded. In a number of cases a decrease in the blood pyruvic acid coincided with a clinical improvement which made it difficult to decide the cause of the fall. A number of cases were, however, satisfactory for the purpose required and are summarized below.

In order to obtain comparable figures, the same technique of sampling and estimation of the pyruvic acid was followed as was used in an earlier study (Allibone and Finch, 1946). The specimens of blood were collected immediately before the mid-day feed. The pyruvic acid was estimated by a modification of the Neuberg-Case method.

\section{Case Reports}

Case 1, suffering from congenital syphilis, showed the persistence in a chronic infection of a high pyruvic acid uninfluenced by thiamine either orally or parenterally.

G. E. whose birth weight was $7 \mathrm{lb} .(3,175$ g.) and who was the first-born, was admitted at the age of two months weighing $9 \mathrm{lb}$. $(4,082 \mathrm{~g}$.). For the past month he had been fretful, had had diarrhoea, and had been noticed to go a waxy colour from time to time. On-admission he was poorly and feverish. The abdomen was slightly distended, and both spleen and liver were enlarged to a depth of three fingers' breadths below the costal margin. The haemoglobin was $5.95 \mathrm{~g}$. per $100 \mathrm{ml}$., erythrocytes 2.5 millions, reticulocytes 4.7 per cent. The child was originally considered to be a case of haemolytic anaemia. His condition, however, rapidly deteriorated, the abdomen becoming more distended, tense and tender. The respirations were grunting as if he were in pain. The question of peritonitis was raised, and he was put on penicillin and given a transfusion of $225 \mathrm{ml}$. blood over a period of two days (fig. 1). Five days after admission, when the mother's blood Wassermann was reported to be positive, he was put on sulpharsphenamine and the 


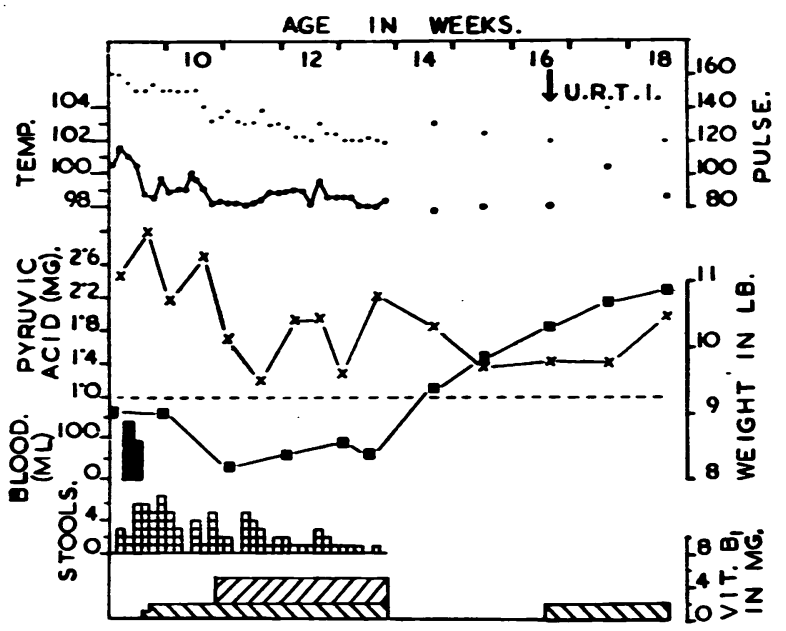

DI ORAL VITAMIN B -W WEIGHT

ZD INJ. THIAMINE $\longrightarrow$ PYRUVIC ACID

Fig. 1. - The persistence in a chronic infection of a high pyruvic acid level uninfluenced by thiamine orally or parenterally (case 1).

penicillin was increased from 48,000 units to 100,000 units intramuscularly daily. He remained poorly and febrile for twelve days. The temperature then came down but did not settle completely, nor was weight gained. The blood pyruvic acid fluctuated similarly and did not seem to be influenced by vitamin B given orally (thiamine $2 \mathrm{mg}$., riboflavin $2 \mathrm{mg}$., nicotinic acid $\mathbf{3 0} \mathrm{mg}$. in two doses daily) or intramuscularly. After discharge weight was slowly gained, but the blood pyruvic acid remained raised above $1.40 \mathrm{mg}$. per $100 \mathrm{ml}$., in association with an attack of coryza accompanied by anorexia and vomiting, culminating in otitis media.

Case 2 showed the raised blood pyruvic acid level associated with a metabolic disturbance and also the questionable effect of vitamin therapy.

B. S. was admitted at the age of three weeks with parenteral diarrhoea due to skin sepsis. The birth weight was $6 \frac{1}{2} \mathrm{lb}$. (2,950 g.). Investigations were started three weeks after admission when the baby was recovering from the diarrhoea. The weight was then $6 \mathrm{lb} .(2,720 \mathrm{~g}$.). Twenty days later the diarrhoea recommenced, the pyruvic acid level remained raised, fluctuating about $1.8 \mathrm{mg}$. per $100 \mathrm{ml}$. Weight gain ceased (fig. 2). With the cessation of the bowel disturbance there followed a more rapid increase in weight accompanied by a fall in the pyruvic acid level to $1.0 \mathrm{mg}$. At the onset of the experiment, two tablets of yeast were given three times a day which was equivalent to $1.8 \mathrm{mg}$. thiamine daily. (three tablets, weighing $1 \mathrm{~g}$., contained thiamine $0.9 \mathrm{mg}$., riboflavin $0.05 \mathrm{mg}$., nicotinic acid 0.25 $0.35 \mathrm{mg}$., and piridoxin 0.025-0.050 mg.). After thirteen days this was changed to thiamine intramuscularly, 70 microgrammes being given eight-hourly for a further fourteen days. As this had no effect, thiamine, $1 \mathrm{mg}$., was administered orally seven times a day after feeds. Twelve days later the thiamine was given intramuscularly, $1 \mathrm{mg}$. eight-hourly. After an interval of seven days the blood pyruvic acid now began to fall.

Comment. The fall in the blood pyruvic acid level was associated with an improvement in the clinical condition as shown by the decrease in the number of stools and the gain in weight. The effect of the vitamin therapy is uncertain. The cause of the relapse remained obscure. There was at no time any pyrexia nor was a parenteral cause found.

Case 3 illustrated the failure of thiamine to - reduce the raised blood pyruvic acid level in a chronic infection which ended fatally.

P. M., a female infant, was admitted at the age of two months with a history of jaundice dating from the age of two weeks. The birth weight was $6 \mathrm{lb}$. $(2,720 \mathrm{~g}$.), the weight on admission was $8 \frac{1}{2} \mathrm{lb}$. (3,850 g.). Development was fairly good; the liver and spleen were just palpable. There was a moderate degree of jaundice, the blood bilirubin being $3.2 \mathrm{mg}$. per 100 $\mathrm{ml}$. Bile pigments were present in the stools. Haemoglobin was $9.9 \mathrm{~g}$. per $100 \mathrm{ml}$., red cells 3.6 millions, reticulocytes 3.6 per cent.

After the baby had been in hospital for nearly three weeks, she suddenly developed a temperature which did not settle. The Mantoux reaction was

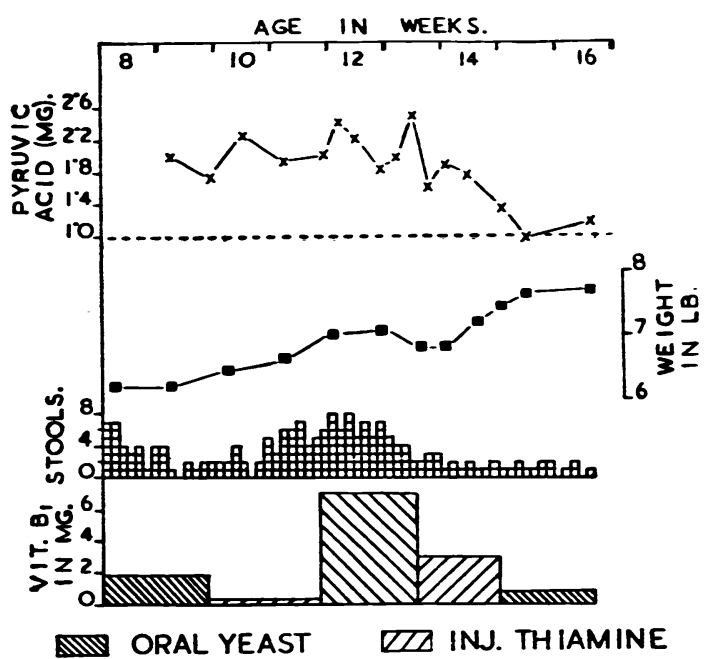

QV ORAL THIAMINE

FIG. 2.-A persistent raised blood pyruvic acid associated with a metabolic disturbance. The questionable effect of vitamin therapy (case 2). 


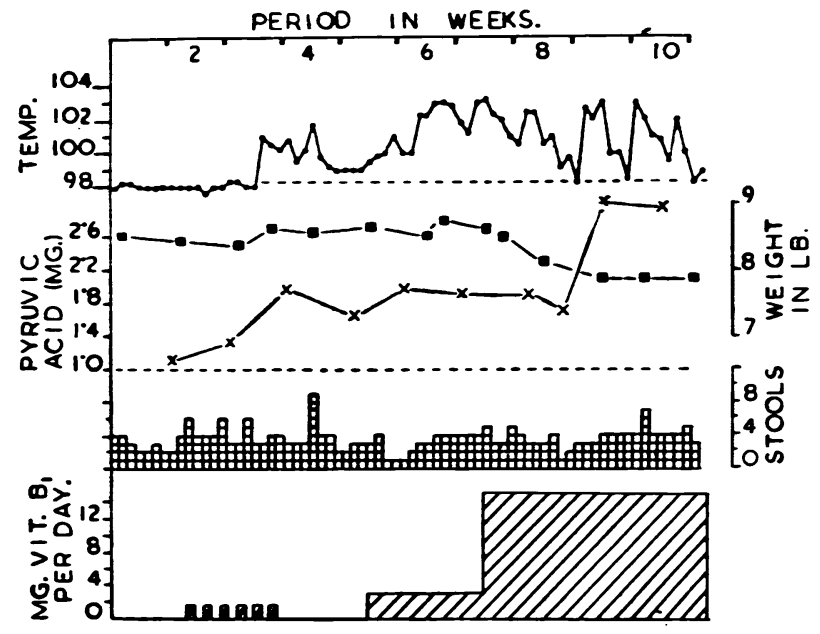

\section{- INJ. VITAMIN B, WITH LIVER - WEIGHT \\ ZZ INJ. THIAMINE \\ $x$ - PYRUVIC ACID}

FIG. 3. - The failure of thiamine to reduce the raised blood pyruvic acid level in a chronic infection with a fatal termination (case 3).

positive and a radiograph of the chest suggested a tuberculous bronchopneumonia.

With the onset of the pyrexia the pyruvic acid level, which had been only slightly elevated, rose to nearly $2.0 \mathrm{mg}$. per $100 \mathrm{ml}$., at which level it remained in spite of parenteral injections of $1 \mathrm{mg}$. thiamine eight-hourly for fourteen days, followed by injections of $5 \mathrm{mg}$. eighthourly for a further twenty-six days. There was a terminal rise of the blood pyruvic acid to $3.0 \mathrm{mg}$. in spite of continued high vitamin therapy (fig. 3). At autopsy the primary focus was found to be in the right lung.

COMment. Although the pyrexia, by elevating the metabolic rate, may have been a factor in the causation of the high blood pyruvic acid, the level had begun to rise before any fever had been recorded. The daily optimal requirements of thiamine, calculated at $0.02 \mathrm{mg}$. per lb. body weight (Knott et al., 1943), were less than 0.20 mg. If a raised metabolic rate had been an important cause, the initial parenteral dose of $3 \mathrm{mg}$. per day would have been amply adequate to restore normality. The blood pyruvic acid level remained uninfluenced not only by this dose but also by the massive amount of $15 \mathrm{mg}$. a day. The terminal rise in the level gave evidence of an impending metabolic eclipse. One must assume in this instance that either a deficiency in thiamine had little to do with the disordered carbohydrate metabolism or that the body was incapable of using the vitamin even when given in large doses.

Case 4 showed the effect on the blood pyruvic acid of an intercurrent infection and also the failure of either oral or parenteral vitamin to achieve normality in the presence of residual sepsis.

P. V. was admitted aged eight months with one week's history of cough, diarrhoea, and vomiting. She had on clinical examination an upper respiratory tract infection which was treated with penicillin, 3,000 units three-hourly for thirty days, and with succinyl sulphathiazole, $1.0 \mathrm{~g}$. four-hourly for twenty-five days. Parenteral fluids were given initially. The diarrhoea settled down after ten days, but the temperature never came down to normal, the pulse averaged 130 and the respirations remained between 39 and 40 per minute. She received throughout the greater part of her stay vitamin B given orally (thiamine $2.0 \mathrm{mg}$., riboflavin 2.0 mg., nicotinic acid $30 \mathrm{mg}$. in two doses daily). This was supplemented between the eleventh and fifty-fourth day by nine yeast tablets daily, which gave an additional intake of $2.7 \mathrm{mg}$. thiamine per day (fig. 4). (Three yeast tablets, weighing $1 \mathrm{~g}$., contained thiamine 0.9 mg., riboflavin 0.05 mg., nicotinic acid 0.25-0.35 mg., and piridoxin 0.025- 0.050 mg.)
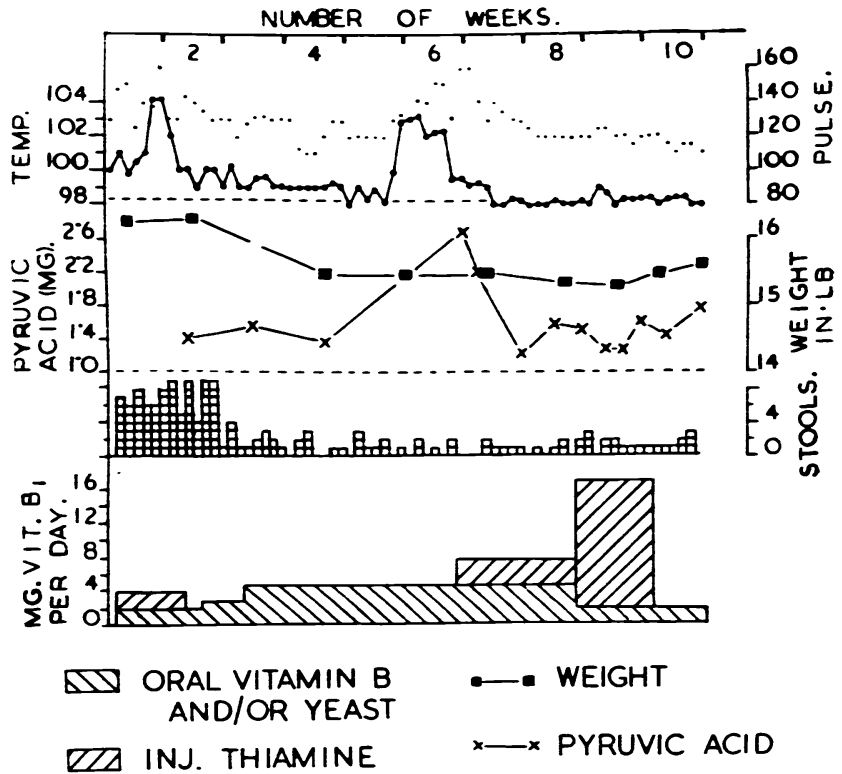

FIG. 4.-The effect on the blood pyruvic acid of an intercurrent infection. Failure of either oral or parenteral vitamin to achieve normality in the presence of residual sepsis (case 4). 
On the thirty-fifth day, four days after the cessation of the penicillin treatment, acute pneumonia developed with a small empyema which was treated with another course of penicillin, 3,000 units eight-hourly for twenty-four days, and sulphadiazine, $0.5 \mathrm{~g}$. six-hourly for twenty days. The blood pyruvic acid level, which had been slightly elevated before the complication, now rose to $2.60 \mathrm{mg}$. per $100 \mathrm{ml}$. of blood but came down to $1.22 \mathrm{mg}$. as the baby became afebrile. In spite of a normal temperature and normal stools, the pulse rate remained at 120 , the respiration rate persisting at 60 for three weeks and still being $\mathbf{4 0}$ per minute on discharge. Serial radiographs of the chest demonstrated that resolution was slow; the weight remained stationary and the blood pyruvic acid showed no evidence of falling to normal figures in spite of an adequate oral intake supplemented by first a moderate parenteral dose of thiamine and finally a massive parenteral dose of $5 \mathrm{mg}$. eighthourly.

Comment. The increased pyruvic acid after a pulmonary complication occurred in the absence of diarrhoea and in spite of a previously generous intake of the whole vitamin B complex. Parenteral thiamine had no influence on the level.

Case 5 was a further illustration of the effects of a febrile episode on the blood pyruvic acid and the questionable and certainly delayed effects of thiamine therapy.

M. C. was admitted as being allegedly of thirtyfour weeks' gestation. Weight on the fourth day

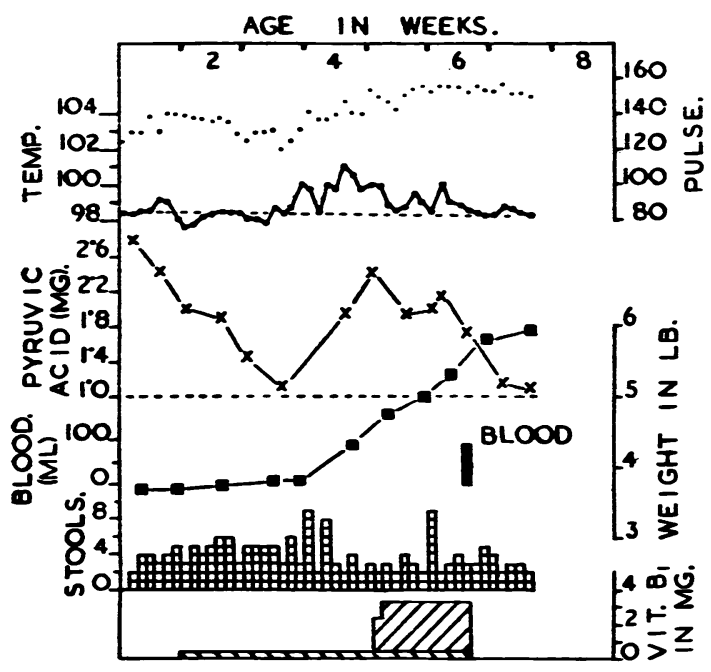

DV ORAL VITAMIN B - W WEIGHT

RZ INJ. THIAMINE $x-x$ PYRUVIC ACID

Fig. 5.-The effect of a febrile episode on the blood pyruvic acid. The questionable and certainly tardy effects of thiamine therapy (case 5). was $3 \mathrm{lb} .11 \mathrm{oz}(1,676 \mathrm{~g}$.). He fed well from birth. Jaundice was present between the third and eighth days. The feed was diluted breast milk with added casein hydrolysate and dextrimaltose.

Although there was no initial gain in weight, the temperature and pulse were satisfactory. The baby seemed well. The blood pyruvic acid level, which on the second day was $2.78 \mathrm{mg}$. per $100 \mathrm{ml}$., fell steadily until by the nineteenth day it had reached $1.12 \mathrm{mg}$. (fig. 5). Two days after this the baby became pyrexial, the pulse rate rose, and feeds were taken unwillingly. The condition was treated as one of infection, though the onset of the disturbance coincided with a heatwave which affected three other premature babies in a similar way though to a less degree. There was a concomitant rise in the blood pyruvic acid to $2.40 \mathrm{mg}$. per $100 \mathrm{ml}$. and weight began to be gained rapidly, which appeared strange until, on the thirty-fifth day, clinical oedema became obvious. The oedema persisted in varying degree and did not seem to be associated in itself with any constitutional disturbance. The baby's clinical condition now improved steadily, the oedema gradually disappeared following a blood transfusion, and the blood pyruvic acid eventually fell to normal.

COMment. The initial high blood pyruvic acid was an exaggerated example of the high levels which occur in full-term babies during the first week of life. In view of the precarious state of the premature baby's metabolic equilibrium, such high figures are no occasion for surprise.

The second fall in the blood pyruvic acid level came at the end of the febrile episode when the clinical condition improved greatly. If the thiamine injections contributed to this fall, the response was delayed. It had previously been noticed that a blood transfusion frequently lowered the level, and for that reason the vitamin therapy was stopped as soon as the transfusion had been given.

Case 6 showed the effect of the whole vitamin B complex on the blood pyruvic acid in a case of coeliac disease in an infant.

R. D. was admitted aged seven weeks with a history of diarrhoea. Birth weight was $5 \mathrm{lb}$. (2,270 g.), and weight on admission $4 \mathrm{lb}$. $6 \frac{1}{2} \mathrm{oz}$. $(2,000 \mathrm{~g}$.). He had always had difficulty with his feeds and there had been previous attacks of diarrhoea.

- After the diarrhoea ceased and dehydration had been relieved, the weight remained stationary. The stools were eventually noticed to be large, pale, and somewhat offensive but not frequent, averaging three a day. At the age of thirteen weeks the fat content of the stools was 63 per cent. of the dried weight, the daily fat output weighing $6.0 \mathrm{~g}$., which was equal to 35 per cent. of the fat content of the feed. The latter consisted of full cream lactic acid milk $14 \mathrm{oz}$ (400 ml.), water $10 \mathrm{oz}$. $(140 \mathrm{ml}$.), and dextrimaltose $1 \mathrm{oz}$. (28 g.) per day. Trypsin was present in the duodenal juice. 


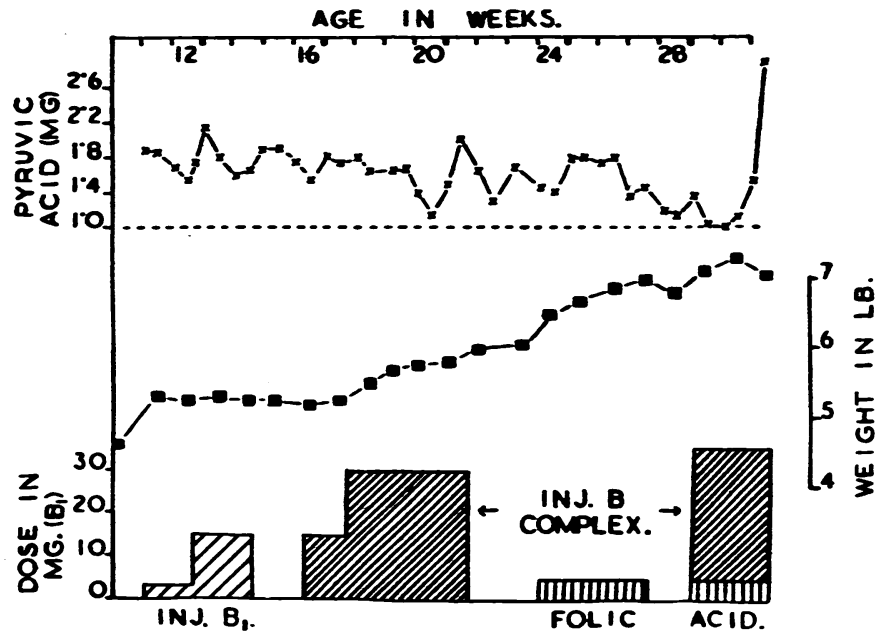

Fig. 6. -The effect of the whole vitamin B complex on the blood pyruvic acid level in a case of coeliac disease in an infant (case 6).

The general condition was reasonably good apart from marasmus and some pallor. The blood pyruvic acid remained elevated, ranging between 1.5 and $2.0 \mathrm{mg}$. per $100 \mathrm{ml}$. (fig. 6). An intramuscular injection of thiamine hydrochloride, $1 \mathrm{mg}$., was given eight-hourty for eleven days, when the dose was increased to $5 \mathrm{mg}$. eight-hourly for a further fourteen days. This was without demonstrable clinical or metabolic effect. After an interval of twelve days intramuscular injections of vitamin B complex were given $(1 \mathrm{ml}$. contained $10 \mathrm{mg}$. of thiamine, $0.5 \mathrm{mg}$. riboflavin, $25 \mathrm{mg}$. niacin amide, $0.5 \mathrm{mg}$. piridoxin, $0.5 \mathrm{mg}$. calcium pantothenate). Initially $1.5 \mathrm{ml}$. was given daily for the first ten days. The dose was then doubled and continued for a further twenty-eight days. The weight now began to increase and continued to do so, though slowly. The pyruvic acid fluctuated between $1 \cdot 13$ and $2.0 \mathrm{mg}$. per $100 \mathrm{ml}$. of blood. When the baby was twenty weeks old the fat comprised 57 per cent. of the dried stool, the daily faecal fat excretion of $4.4 \mathrm{~g}$. being 24 per cent. of the fat ingested. After a rest from therapy for sixteen days, he was given $5 \mathrm{mg}$. folic acid orally daily for twenty-five days, by the end of which period the blood pyruvic acid had gradually fallen to $1.20 \mathrm{mg}$. per $100 \mathrm{ml}$. The faecal fat comprised 42.5 per cent. of the dried stool. The daily output of $2.0 \mathrm{~g}$. was equivalent to 11 per cent. of the fat intake. Following another therapeutic rest period of ten days the folic acid, orally and in the same dosage, was administered for eighteen days together with daily intramuscular injections of $3.0 \mathrm{ml}$. of the preparation of vitamin $B$ complex previously given. Within a week the pyruvic acid, for the first time since the investigation started, fell to $1.0 \mathrm{mg}$. per $100 \mathrm{ml}$. blood. The pyruvic acid level now began to rise without any apparent reason, and within a week reached what was for this case a record height of $2.90 \mathrm{mg}$. The temperature, pulse, and respiration remained normal, though the weight fell from $7 \mathrm{lb} .7 \mathrm{oz}$ $(3,360 \mathrm{~g}$.) to $7 \mathrm{lb} .1 \mathrm{oz} .(3,190 \mathrm{~g}$.) within three days. The following day he was taken home at the parent's request. Twenty-four hours later he choked while being fed and died. Autopsy revealed enteritis, toxic hepatitis and chronic interstitial pneumonia. Histologically the pancreas was normal as were the other organs except those mentioned above.

Comment. In this infant, who was the youngest case of coeliac disease diagnosed at this hospital, the raised pyruvic acid may have been due to a deficiency of factors all of which were contained in the vitamin B complex, including the folic acid. In the presence of his terminal infection they were, however, incapable of maintaining equilibrium. Of interest is the absence of any clinical evidence that he was going downhill, apart from the loss in weight, yet the blood pyruvic acid had been rising for four days before he died.

Case 7 was a further demonstration of the effects of a complication on the intermediate metabolism of carbohydrate.

T. D. was admitted at the age of three weeks with parenteral diarrhoea due to an upper respiratory

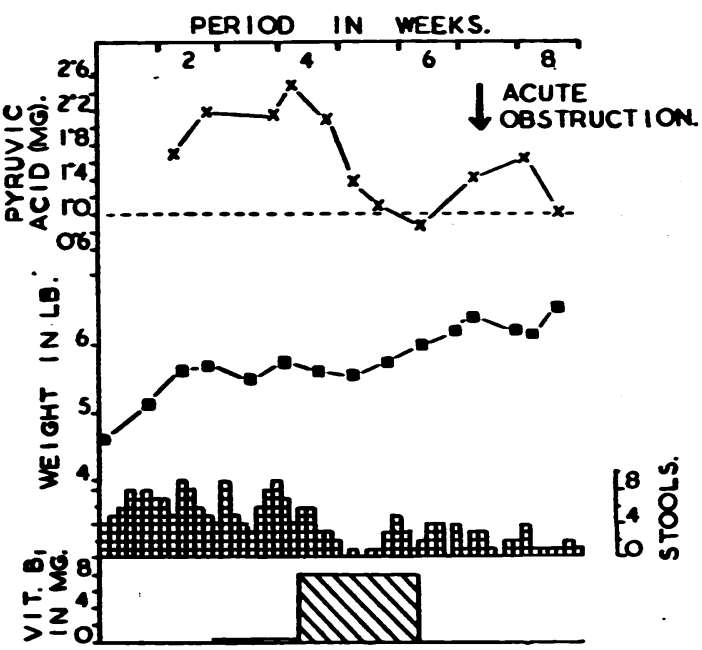

ED IN. THIAMINE DV ORAL THIAMINE

Fig. 7.-Demonstration of the effect of a surgical complication on the intermediate metabolism of carbohydrate (case 7). 
tract infection. After hydration had been achieved, the weight remained stationary until the diarrhoea ceased in the fourth week, after which weight was gained. Commencing on the fourteenth day, $0.07 \mathrm{mg}$. thiamine hydrochloride was given by intramuscular injection eight-hourly for ten days without appreciable effect. The total daily requirement of thiamine was about $0.12 \mathrm{mg}$. This therapy was followed by $1 \mathrm{mg}$. thiamine orally eight times daily after feeds. It coincided with the cessation of the diarrhoea and with a fall of the pyruvic acid to a normal level of $0.87 \mathrm{mg}$. (fig. 7). When treatment was stopped the blood level rose instead of remaining down, as one would have expected in view of the improvement in the clinical condition as reflected in the cessation of diarrhoea and commencing weight gain. On the forty-fifth day after admission a large

TABLE 1

BLOOD PYRUVIC ACID LEVELS IN A SERIES OF NORMAL NEWBORN INFANTS DURING THE FIRST WEEK OF LIFE

\begin{tabular}{l|c|c|c}
\hline \multirow{2}{*}{ Name } & \multicolumn{3}{|c|}{ Age in days } \\
\cline { 2 - 4 } & 1 & $4-5$ & $7-8$ \\
\hline Th. & 2.75 & 1.25 & 1.44 \\
Te. & 2.27 & 1.37 & 0.93 \\
Cu. & 2.26 & 1.75 & 1.25 \\
Li. & 1.85 & 1.28 & 1.18 \\
We. & 1.66 & 1.30 & 1.07 \\
Da. & 1.46 & 1.28 & 1.38 \\
Cn. & 1.26 & 1.72 & 0.92 \\
& & & \\
\hline
\end{tabular}

Pyruvic acid given in me per $100 \mathrm{ml}$ blood.

right inguinal hernia, which had been present before coming into hospital, strangulated. Though the blood pyruvic acid subsequently rose a little higher, it had fallen to a normal value of $1.0 \mathrm{mg}$. within nine days of the operation for relief of the strangulation and without the addition of extra vitamin.

Comment. One might assume that the rise in pyruvic acid before the strangulation was due to the cessation of oral therapy. It must, however, be remembered that cows' milk, even after allowing for loss in pasteurization, still contains approximately twice the quantity of thiamine in human milk (Lawrence et al., 1945). At this phase the diarrhoea had settled and weight was being gained. There was no deficiency of thiamine in the diet and no apparent call for extra vitamin. That the dietary intake was adequate under normal circumstances was seen by the return to normal values once recovery from the effects of the obstruction had occurred. Although the idea may at first appear improbable, it seems as if the rise in the blood pyruvic acid at this time was associated with a metabolic disturbance which found its clinical culmination in acute intestinal obstruction. This elevation of the pyruvic acid level occurring before a clinical event, in the nature of "writing on the wall,' was also seen in the ante-mortem rise in cases 3 and 6.

\section{The Blood Pyruvic Acid Level in Hacmolytic Amenia in Infancy}

It was possible to estimate the blood pyruvic acid in seven cases of icterus gravis during the first five days of life. The figures were respectively $1 \cdot 16$, $1.92,1 \cdot 86,3 \cdot 26,1 \cdot 93,1 \cdot 50$, and $2.06 \mathrm{mg}$. per $100 \mathrm{ml}$. of blood.

The interpretation of the raised pyruvic acid level in such cases was rendered difficult by the numerous factors involved. Normal newborn infants have a raised blood pyruvic acid which usually approaches normal values by the end of the first week (table 1). The toxic action on the liver, as evidenced by the

TARUE 2

BLOOD PYRUVIC ACID LEVELS IN CASES WITH HAEMOLYTIC ANAEMIA WITHOUT JAUNDICE

\begin{tabular}{|c|c|c|c|c|c|}
\hline Name & $\begin{array}{c}\text { Cause } \\
\text { of } \\
\text { anaemia }\end{array}$ & $\begin{array}{c}\text { Age } \\
\text { in } \\
\text { days }\end{array}$ & $\begin{array}{l}\text { Hb: on } \\
\text { admis- } \\
\text { sion }\end{array}$ & $\begin{array}{c}\text { Reticulo- } \\
\text { cytes } \\
(\%)\end{array}$ & $\begin{array}{c}\text { Pyruvic } \\
\text { acid } \\
\text { mg. } \%\end{array}$ \\
\hline $\begin{array}{l}\text { J.W. } \\
\text { S.B. } \\
\text { R.M. } \\
\text { B.B. } \\
\text { D.E. } \\
\text { M.K. }\end{array}$ & $\begin{array}{c}\text { H.D.N.B. } \\
\text { "" } \\
\text { " } \\
\text { ? } \\
\text { Nephritis }\end{array}$ & $\begin{array}{l}57 \\
27 \\
73 \\
45 \\
56 \\
92\end{array}$ & $\begin{array}{l}52 \\
47 \\
64 \\
65 \\
42 \\
42\end{array}$ & $\begin{array}{r}9 \cdot 0 \\
34 \cdot 8 \\
13 \cdot 2 \\
14 \cdot 6\end{array}$ & $\begin{array}{l}2 \cdot 50 \\
3 \cdot 50 \\
3 \cdot 10 \\
1 \cdot 85 \\
2 \cdot 35 \\
1 \cdot 88\end{array}$ \\
\hline
\end{tabular}

H.D.N.B. = Hremolytic diease of the newborn.

deep jaundice, in icterus gravis may affect pyruvate metabolism as the liver and kidney convert thiamine into its active form, cocarboxylase. Liver damage has been shown to interfere with thiamine metabolism (Allibone and Finch, 1945). Davis and Bauer (1944) found raised blood pyruvic acid levels in hepatic disease.

In view of the difficulty of assessing the significance of the raised blood pyruvic acid in icterus gravis during the first week of life, six older infants were collected who had a haemolytic anaemia, but no jaundice. Three cases had had icterus gravis and were admitted with an exacerbation of the haemolytic process; in one case there was an acute haemorrhagic nephritis thought to be a sequel to a streptococcal tonsillitis. In two the cause was unknown. All infants in this group had a raised blood pyruvic acid, the average figure being $2.53 \mathrm{mg}$. per $100 \mathrm{ml}$. of blood (table 2).

After a blood transfusion the blood pyruvic acid fell in every case except one. The level, however, rose immediately in those cases where the haemolytic process persisted, necessitating further transfusion, or where a toxic or infective state complicated the picture. The results of blood transfusion on the pyruvic acid level in cases of haemolytic anaemia 
TABLE 3

\section{EFFECT OF BLOOD TRANSFUSION ON THE BLOOD PYRUVIC ACID LEVEL IN CASES OF} HAEMOLYTIC ANAEMIA

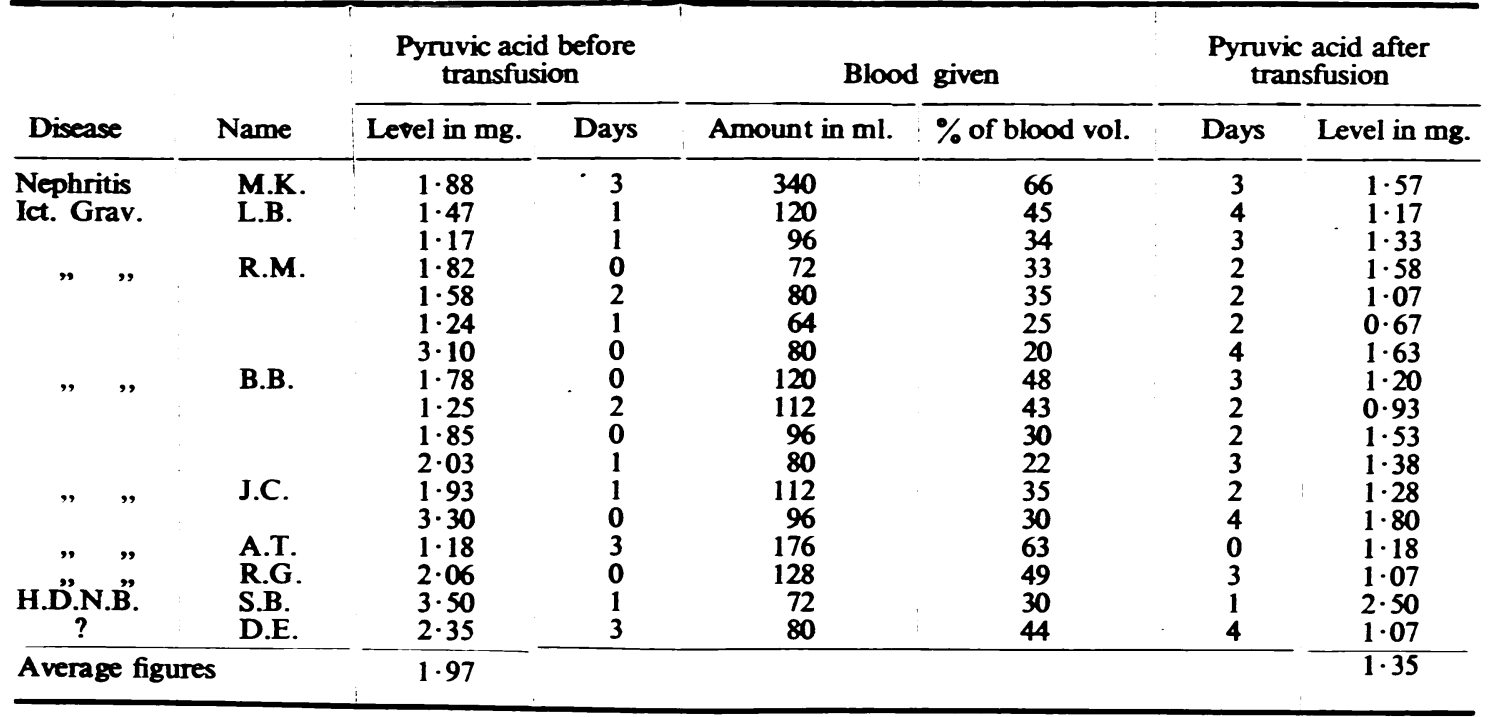

are given in table 3 . The action of persistent haemolysis in a particular infant are well illustrated in the following case.

Case 8, with icterus gravis, demonstrated the effect on the blood pyruvic acid of repeated blood transfusion.

B. B. was admitted when one day old, jaundice being noticed immediately after birth. She was the second child, the first being normal. The blood group was $O R h$ positive. The reactions with strong anti $\mathrm{Rh}$ sera were very weak, the erythrocytes

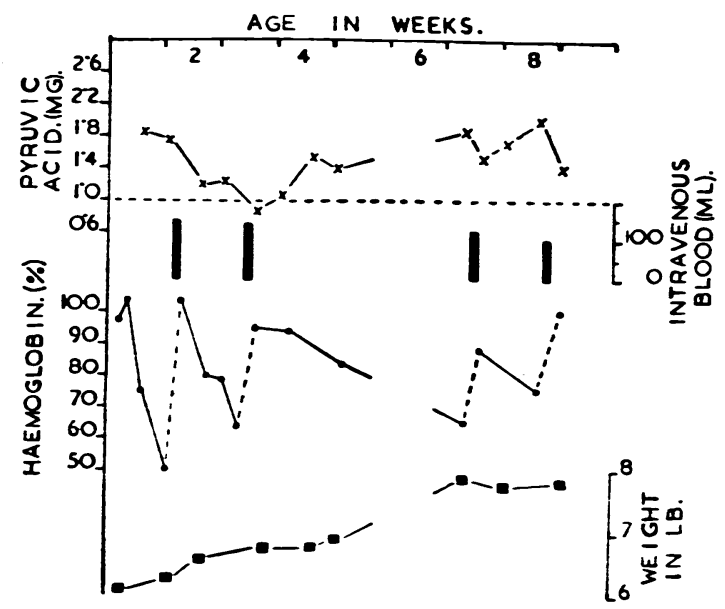

Fig. 8. - The lowering of the blood pyruvic acid by blood transfusion (case 8). being blocked by incomplete antibodies. The conglutinin test with the baby's serum was positive, as were the sensitization tests with antihuman globulin serum and with concentrated AB serum. Initially there was a rapid haemolysis, the haemoglobin falling from 104 per cent. to 50 per cent. in five days. Although the jaundise h?d disappeared by the fourth week and the bavy was well enough to be allowed home, the haemolytic process persisted to a less degree, readmission being necessary in the seventh week and four transfusions being given in all before a stable blood picture was achieved (fig. 8). After each transfusion there was a fall in the blood pyruvic acid, this being only temporary in the case of the first three transfusions.

\section{Discussion}

Glucose, when completely metabolized to carbon dioxide and water, goes through a sequence of stages which have been identified as far as pyruvic acid. For the further breakdown there are several possible ways, dismutation to lactic and acetic acids, decarboxylation to acetaldehyde, oxidation to acetic acid or oxidation of pyruvic acid phosphate to acetyl phosphate and also conversion to oxaloacetic acid by carbon dioxide fixation. Although all these reactions occur in either lower animals or in bacteria, the method in man is as yet unknown (Stotz, 1945), but it is thought that pyruvic acid is carboxylated to oxaloacetic acid, which is then utilized in two cycles, the citric acid or the succinic acid (Bicknell and Prescott, 1946). The enzyme system catalyzing these reactions comprises a number of components which include inorganic 
phosphate, metallic ions, manganese, magnesium, or cobalt, protein, and one or more factors of the vitamin B complex. A number of interrelationships have been shown to exist between thiamine and the other vitamins. In chronic thiamine deficiency there is a lowered retention of riboflavin with increased loss in the urine (Sure, 1944). In rats depletion of thiamine is associated with an increased concentration of riboflavin in the liver (Singher et al,, 1944). The association of biotin and pantothenic acid with pyruvic acid metabolism was shown by a decreased oxygen consumption in the presence of pyruvate by homogenates of liver from pantothenic and biotin deficient rats (Pilgrim et al., 1942). The addition of small amounts of biotin under such circumstances accelerated the removal of the substrate (Summerson et al., 1944).

An accumulation of pyruvic acid in the blood may be caused either by retardation in its breakdown to carbon dioxide and water or by failure of resynthesis to glucose. Whatever the process, the number of factors participating in these reactions are sufficiently numerous to indicate that a raised blood pyruvic acid cannot be considered synonymous with thiamine deficiency. Williams et al. (1943) considered that a high blood pyruvic acid after the ingestion of glucose signified a vitamin deficiency, provided insulin hypoglycaemia, hyperthyroidism, mild diabetes, and other factors related to carbohydrate metabolism could be excluded. On the grounds given in the previous paragraph, this manoeuvre does not render the test more specific although it may become more delicate. Lu and Platt (1939) achieved a similar effect by estimating the blood pyruvic acid after exercise.

In none of the infants in this series of cases was there reason to suspect beriberi nor could either clinical or metabolic improvement be definitely attributed to the vitamin therapy. On the other hand cases of beriberi respond dramatically to thiamine. Platt and Lu (1939) found that the removal of pyruvic acid from the blood on giving thiamine was initiated after a lag of about four hours, the time interval being due to the conversion of thiamine into its active form cocarboxylase. In adults with acute beriberi a single dose of from 5 to $10 \mathrm{mg}$. of thiamine reduced blood pyruvate levels of 3.0 to $5.0 \mathrm{mg}$. to normal in about ten hours. In a fatal case of a boy with congestive heart failure due to beriberi, with cirrhosis of the liver and terminal pericarditis, previously reported by Allibone and Baar (1946), 12.5 mg. thiamine was given by intramuscular injection in divided doses daily. The blood pyruvic acid fell from 1-97 to $1.13 \mathrm{mg}$. per $100 \mathrm{ml}$. in twenty-four hours. Three days later, on the day before death, it was $0.70 \mathrm{mg}$. (fig. 9). In view of the imminence of his decease it is remarkable that the blood pyruvic acid level was affected at all. This result contrasted with the effect of intramuscular injections of thiamine given in cases $1,2,3$, and 5 , where no fall in the blood pyruvic acid occurred. In case 4 the level began to fall after a lag of seven days following the administration of intramuscular thiamine equivalent to 500 microgrammes per lb. body weight. Yeast, the calculated daily optimum dose of thiamine given intramuscularly, and massive oral thiamine therapy all failed to influence the pyruvic acid level in case 2 . During the administration of thiamine intramuscularly in larger doses equivalent to 500 microgrammes per $\mathbf{l b}$. body weight, the level began to fall after an interval of seven days.

The difference in the response of the blood pyruvic acid to the administration of thiamine, between these cases of marasmus and chronic infection in

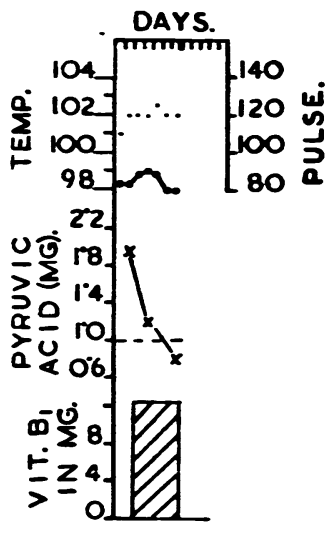

\section{ZZI INJ. THIAMINE}

Fig. 9.-The rapid fall in the blood pyruvic acid in a case of beriberi following treatment with Vitamin $B_{1}$.

infancy on the one hand and those cases of beriberi on the other, left no doubt that thiamine deficiency played little part in the etiology of the raised level in the former. Owing to the relationship between thiamine and the other components of the vitamin B complex, the possibility existed that a lack of part of the remaining or thermostable fraction might be responsible for the abnormality in carbohydrate metabolism in these cases. That this might be so was suggested from the course of $R$. D. (case 6), the infant with coeliac disease, whose blood pyruvic acid seemed to be settling to normal when he was given vitamin B complex plus folic acid. The fall was, however, in no way dramatic, and the rapid antemortem rise while the child was still receiving treatment showed his metabolic instability. Further, the treatment of sixteen cases of coeliac disease with high doses of vitamin B complex, $4 \mathrm{ml}$. intramuscularly every other day for three and in some cases six weeks, produced no change in the blood pyruvic acid (Allibone, 1946). (1 ml. contained $10 \mathrm{mg}$. thiamine, $0.5 \mathrm{mg}$. riboflavin, $25 \mathrm{mg}$. niacin amide, $0.5 \mathrm{mg}$. piridoxin, $0.5 \mathrm{mg}$. calcium pantothenate.) It cannot, therefore, be maintained that the breakdown in carbohydrate metabolism in the infants under 
discussion could be attributed to a deficiency of any of the known components of the vitamin B complex. Whatever may be the cause, its elucidation will contribute materially to the understanding of the mechanism of the intermediate metabolism of glucose.

The raised blood pyruvic acid in the newborn was not thoroughly investigated. Although the probable cause was a temporary disorganization of metabolism following birth, other possibilities have to be considered. In rabbits $(\mathrm{Lu}, 1939)$ and in man (Johnson and Edwards, 1937) the blood pyruvic acid is raised after exercise. It is likely that during labour the blood pyruvic acid in the mother will be raised, and that this increase would be shown in the blood of the newborn. As normal values are reached again within an hour after exercise, this factor should not operate after the first day.

The presence of ketosis will give high values. The colorimetric method used for the determination of pyruvic acid was based on the isolation of sodium pyruvate 2,4-dinitrophenylhydrazone and the reaction of the latter with strong alkali to form a red derivative. The corresponding hydrazones of acetone and acetoacetic acid give a similar red colour with alkali. As a result a ketosis gave erroneously high values for pyruvic acid. It was, therefore, our practice to abandon the estimation in the presence of ketonuria. Sometimes, however, it was impossible to obtain a specimen of urine in a newborn infant, particularly in a female. Bueding et al. (1941) suggested that allowing the ethyl acetate extract to stand overnight in the refrigerator would allow the hydrazones of acetoacetic acid and acetone to be destroyed. The writer's experience with this modification of the method was not successful. In cases with ketonuria, after a duplicate had stood overnight, the result next day was on several occasions even higher than the sample estimated the day before. Klein (1941) substituted tungstic acid for trichloracetic acid as the protein precipitant and allowed the ethyl acetate extract to stand for eighteen to twenty-four hours in the refrigerator. In this way the acetoacetate hydrazone decomposed, leaving the pyruvate hydrazone intact. This modification is indicated whenever there is a likelihood of ketosis being present.

The causation of the high pyruvic acid level in haemolytic states may be due to several factors not previously discussed. Evidence for the destructive action by a haemolytic process on thiamine in the blood has been given. Where the haemoglobin has fallen considerably, the anoxaemia may interfere with the oxidation of pyruvic acid. The toxaemia associated with the haemolysis may depress not only those enzymes concerned with the disintegration of pyruvic acid but also those which may help to resynthetize the acid to glucose. This concept was supported by the lack of response of the blood pyruvic acid to blood transfusion in those cases with a severe constitutional disturbance, as was seen in G. E. (case 1). The possibility that the fall might be a dilution phenomenon, due to a low pyruvic acid in the donor's blood, had to be considered. The occasional high blood pyruvic acid following transfusion was against such an explanation. The pyruvic acid level in stored blood from a healthy donor depended on the time it had been kept in the refrigerator. It appeared that the catabolism of glucose continued as far as the pyruvic acid stage rather faster than beyond it. The pyruvic acid, in consequence, rose for about a week and then, all sources of pyruvic acid having been exhausted, the level began to fall (table 4). Blood from a healthy donor, therefore, contains potentially the same amount of pyruvic acid during the first week of storage. As the pyruvic acid estimation following transfusion was usually performed after an interval of two to three days, adequate time was allowed for stabilization to take place. In normal animals an excess of pyruvate can be removed from the blood in half an hour ( $\mathrm{Lu}, 1939)$. It seems, therefore, probable that the transfused blood,

TABle 4

THEEFFECT OF STORAGE IN A REFRIGERATOR ON THE PYRUVIC ACID LEVEL IN BLOOD TAKEN FROM A HEALTHY DONOR

\begin{tabular}{c|c|c|c|c}
\hline \multirow{2}{*}{ Name } & \multicolumn{4}{|c}{ Duration of storage in days } \\
\cline { 2 - 5 } & 0 & 3 & 6 & 10 \\
\hline Gl & 0.93 & $2 \cdot 27$ & 2.63 & 1.63 \\
Ha & 1.13 & 2.34 & 2.69 & 1.72 \\
\hline
\end{tabular}

Pyruvic acid in mg. per $100 \mathrm{ml}$

by removing or mitigating one or more of the causes contributing to the raised level in the patient's blood, was able to produce a temporary fall in the patient's blood level in the not too severe cases (B. B., case 8) and even initiate or potentiate a permanent reduction in those cases which had entered into the stage of convalescence, as with M. C., case 5.

There seems little doubt that the disordered intermediate carbohydrate metabolism, as evidenced by an elevation of the blood pyruvic acid, which is seen in toxaemic and haemolytic states in infancy, is not due to deficiency of vitamin B. On the other hand the raised blood pyruvic acid level in beriberi falls quickly when thiamine is given. It is suggested that, where in any case the resting blood pyruvic acid is raised, the response of the level to the administration of vitamin B would constitute a therapeutic test for the presence or otherwise of a deficiency of the vitamin.

Lu (1939) found no abnormality of the resting blood pyruvic acid in cases of the "atrophic type" 
of beriberi, which presented only nervous manifestations, although after exercise the raised level returned to normal more slowly than in healthy individuals ( $\mathrm{Lu}$ and Platt, 1939). Bueding et al. (1941) reported that when glucose was given to thiamine-deficient subjects, the blood pyruvic acid rose to a higher level and remained elevated for a longer period than was the case with controls. If this test were to be performed before and after saturating the body with vitamin $B$, it should distinguish subclinical states of true vitamin deficiency from other conditions causing dysfunction of intermediate carbohydrate metabolism.

\section{Summary}

The raised blood pyruvic acid level encountered during infancy in toxaemia and haemolytic states is not associated with a deficiency of thiamine and is probably unrelated to any of the known factors in the vitamin B complex.

The implication of the above findings in relation to the intermediate metabolism of carbohydrate is discussed.

A test for the diagnosis of subclinical states of thiamine deficiency is suggested.

Thanks are due to the Honorary Staff of the Children's Hospital, Birmingham, for permission to work on their cases.
Abbasy, M. A., Harris, L. J. and Hill, N. G. (1937). Lancet, 2, 177.

Allibone, E. C. (1946). Proc. roy. Soc. Med., 39, 700.

— and Baar, H. S. (1946). Arch. Dis. Childh., 21, 76. and Finch, E. (1945). Ibid., 20, 169.

- (1946). Ilbid., 21, 165.

Bicknell, F. and Prescott, F. (1946). The Vitamins in Medicine, London, p. 164.

Bueding, E., Stein, M. H. and Wortis, H. (1941). J. biol. Chem., 140, 697.

Davis, H. A. and Bauer, F. K. (1944). Arch. Surg., 48, 185.

Johnson, R. E. and Edwards, H. T. (1937). J. biol. Chem., 118, 427.

Klein, D. (1941). Ibid., 137, 311.

Knott, E. M., Kleiger, S. C. and Schultz, F. W. (1943). J. Pediat., 22, 43.

Lawrence, J. M., Herrington, B. L. and Maynard, L. A. (1945). Amer. J. Dis. Child., 70, 193.

Lu, G. D. (1939). Biochem. J., 33, 774. and Platt, B. S. (1939). Ibid., 33, 1538.

Mills, C. A. (1943). Proc. Soc. exp. Biol., N.Y., 54, 265.

Pilgrim, F. J., Axelrod, A. E. and Elvehjem, C. A. (1942). J. biol. Chem., 145, 237.

Platt, B. S. and Lu, G. D. (1939). Biochem. J., 33, 1525.

Sinclair, H. M. (1939). Proc. roy. Soc. Med., 32, 812.

Singher, H. O., Kensler, C. J., Levy, H., Poore, E., Rhoads, C. P. and Unna, K. (1944). J. biol. Chem., 154, 69.

Stotz, E. (1945). Advances in Enzymology, 5, 129.

Summerson, W. H., Lee, J. M. and Partridge, C. W. H. (1944). Srience, 100, 250.

Sure, B. (1944). J. Nutrit., $27,447$.

Williams, R. D., Mason, H. L. and Wilder, R. M. (1943). Ibid., 25, 71. 